\title{
Evidências Acústicas da Laringalização Vocálica na Língua Tuparí
}

\author{
Acoustic Evidences of Voicalic Laringalization in the Tuparí \\ Language \\ Fábio Pereira Couto ${ }^{1}$ \\ Edineia Aparecida Isidoro ${ }^{2}$
}

Recebido em abril de 2018

Aceito em maio de 2018

\section{Resumo:}

O presente artigo descreve a ocorrência de laringalização nas vogais da língua Tuparí (ISO 639-3), pertencente à família linguística Tuparí (tronco Tupí). Com a utilização de aparato técnico, metodológico e teórico da fonética acústica analisamos os dados disponíveis, o que possibilitou evidenciar a realização de traço laringal (glotal) nas vogais do Tuparí. Verificamos que a laringalização está presente nas vogais do sistema da língua e que é motivada principalmente pela contiguidade da consoante oclusiva glotal [?] a essas vogais. Parte dos dados usados foram obtidos junto a professores Tuparí na Terra Indígena Rio Branco, em 2018. Outros dados foram gravados em estúdio profissional, em 2016, na Universidade de Brasília.

Palavras-chave: Língua Tuparí. Laringalização. Fonética Acústica. Oclusiva Glotal.

\begin{abstract}
:
The present paper describes the occurrence of laryngalization in Tuparí vowels (ISO 6393), a language belonging to the Tuparí family (Tupí stock). As for the analysis of the data we have made use of a technical, methodological and theoretical apparatus of acoustic phonetics, what made it possible to evidence the realization of a laryngeal tract (glottal) in the Tuparí vowels. We have verified that vowel laryngalization in this language is mainly motivated by the contiguity of a glottal stop [?]. Part of the data data used were obtained among Tuparí teachers at the Rio Branco Indigenous Reservation, in 2018. Other data were collected in a professional studio, in 2016, at the University of Brasília.
\end{abstract}

Keywords: Tuparí language. Laryalization. Acoustic phonetics. Glottal occlusive.

${ }^{1}$ Professor da Fundação Universidade Federal de Rondônia (UNIR) e pesquisador do Laboratório de Línguas e Literaturas Indígenas da Universidade de Brasília (LALLI-UnB).

${ }^{2}$ Professora titular da Universidade Federal de Rondônia (UNIR) e pesquisadora do Laboratório de Línguas e Literaturas Indígenas da Universidade de Brasília (LALLI-UnB). 


\section{Introdução}

A língua Tuparí foi a primeira das línguas Tupí a ter um esboço gramatical construído. Trata-se do trabalho de autoria de Caspar e Rodrigues, cuja primeira versão em alemão data de 1957, intitulada Versuch einer Grammatik der TuparíSprache. No ano de 2017, este estudo valoroso foi traduzido para o português e publicado pelo Laboratório de Línguas e Literaturas Indígenas, da Universidade de Brasília, sob o título "Esboço da Língua Tuparí". Outros estudos sobre a língua Tuparí foram realizados, dentre eles, uma dissertação de mestrado (Alves 1991) e uma tese de doutorado de (Alves 2004). No primeiro, a pesquisadora realiza uma análise fonética e fonológica da língua Tuparí, e no segundo propõe um estudo sobre o léxico dessa língua, antecedido de um esboço gramatical, com base nas contribuições de Rodrigues e Caspar, mas também a partir de dados coletados pela autora entre 1990 e 2004. A pesquisadora Lucy Seki (2002) escreveu sobre "Aspectos Morfossintáticos do Nome em Tuparí" e contribuiu com a produção de material didático para a alfabetização em Tuparí.

No tocante à classificação genética da língua Tuparí, de acordo com Rodrigues (2002, p. 46), a língua Tuparí pertence ao tronco linguístico Tupí e à família Tuparí. A família Tuparí conta ainda com outras cinco línguas, a saber: Makuráp, Wayoró (Ajurú), Kampé, Mekém/Sakurabiát, Akunsú (cf. Cabral e Aragon 2004a, 2005, Rodrigues 2007), todas essas línguas são faladas no estado de Rondônia.

O povo Tuparí vive na Terra Indígena Rio Branco e na Terra Indígena Rio Guaporé, a primeira tem uma extensão territorial de 236.137,1100 hectares $\left(\right.$ FUNAI $^{3}$ ), fica localizada nos municípios de Alta-Floresta, São Miguel do Guaporé e São Francisco do Guaporé, sendo maior a extensão da Terra Indígena Rio Branco, no município de São Francisco do Guaporé e São Miguel do Guaporé. A maioria da população tem mais proximidade com o município de Alta Floresta D'Oeste, pela facilidade do acesso. Nesta, além dos Tuparí, vivem representantes de mais nove etnias, a saber: Arikapú, Aruá, Djeoromitxí, Kanoé, Jiahúi, Tenharím, Sakurabiát, Kampé, Ajurú e Makuráp (Tuparí 2015). Os Tuparí se organizam em várias aldeias, onde a maioria da população é Tuparí e a Língua Tuparí é a mais utilizada na comunicação. Já a Terra Indígena Rio Guaporé está localizada no município de Guajará-Mirim, e possui uma extensão territorial de 115.788.084 hectares (FUNAI 20184). A configuração sociolinguística desta TI é bem parecida com a TI Rio Branco, pois nela convivem várias etnias, quais sejam: Makuráp, Djeoromitxí, Kanoé, Ajurú, Kujubím, Aruá, Tuparí, Kassupá, Arikapú e Oro-Nao' (Makuráp 2015). Nessa T.I., os Tuparí vivem com aproximadamente

\footnotetext{
${ }^{3}$ Dados obtidos em maio de 2018 no site oficial da Funai: <http://www.funai.gov.br/index. php/indios-no-brasil/terras-indigenas $>$.

${ }^{4}$ Dados obtidos em maio de 2018 no site oficial da Funai: <http://www.funai.gov.br/index. php/indios-no-brasil/terras-indigenas $>$.
} 
60 pessoas. Nesta aldeia a língua Tuparí já não está sendo utilizada como língua de comunicação, apenas os mais velhos falam a sua língua nativa, e os mais jovens a entendem mais não a utilizam na comunicação

Este trabalho pretende contribuir com os estudos linguísticos sobre a língua Tuparí, compartilhando os resultados de uma pesquisa de natureza acústico e experimental, com foco na investigação de presença de traço laringal (glotal) nas vogais do Tuparí. Por fazer uso de aparato técnico e metodológico da fonética experimental, a presente pesquisa se distingue das realizadas anteriormente sobre o mesmo tema.

O suporte teórico utilizado para fundamentar a pesquisa advém, principalmente, dos estudos de Gordon e Ladefoged (2001), Ladefoged e Maddieson (1996), Ladefoged (1971, 1971, 1975, 2001), Maddieson (2011), Kent e Read (2015), Barbosa e Madureira (2015), Alves (1991 e 2004), Caspar e Rodrigues (2017) e Telles (2013).

O presente artigo está organizado da seguinte maneira: (i) Informação sobre a geração de dados e todo o processo metodológico que foi utilizado nas análises dos dados acústicos; (ii) Descrição dos quadros fonológicos das vogais e consoantes da língua Tuparí e descrição do padrão básico silábico da língua; (iii) Apresentação de um breve panorama sobre as características acústicas da oclusiva glotal [?]; (iv) Análise acústica das realizações laringalizadas (glotalizadas) das vogais do Tuparí; e (v) Considerações finais sobre os resultados do estudo.

\section{Geração dos dados e metodologia}

Como procedimento metodológico para a formação das medidas físicas dos dados de análise do presente trabalho, nos preocupamos em gravar em ambiente o mais controlado possível, pois não tivemos a oportunidade de gravar todos os dados em estúdio e/ou ambiente insonorizado. Grande parte dos dados foram gerados em aldeias indígenas, e em oficina realizada entre os dias 06 a 12 de abril de 2018, sob a orientação da professora Dra. Ana Suelly Arruda Câmara Cabral. Nesses momentos de gravação fora de estúdio, procuramos gravar os dados em local que evitasse, ao máximo, interferências externas que pudessem prejudicar os dados para a análise acústica. Preocupamo-nos também em criar contextos para obtenção de dados que nos permitissem a análise do foco de nossa pesquisa, com base em fatores que evolvesse principalmente: (i) natureza de duração da vogal - longa ou curta; (ii) grau de tonicidade da vogal - tônica ou átona, e extensão da palavra - monossilábica, dissilábica, trissilábica etc. Com relação aos perfis dos colaboradores indígenas, a gravação dos dados foi feita junto a cinco colaboradores indígenas, sendo uma criança do sexo masculino com idade de nove anos, uma jovem do sexo feminino com 20 anos de idade, e dois adultos do sexo masculino de 77 anos e 41 anos de idade, respectivamente. 
Para verificar as médias de F1, F2 e duração, só utilizamos dados do colaborador masculino de 41 anos, pois somente com esse colaborador, tivemos a oportunidade de fazer gravação em estúdio no ano de 2016.

Para esta pesquisa, contamos com corpora constituído de palavras soltas, sentenças e narrativas. As palavras soltas foram levantadas com base em uma lista lexical semiestruturada. Além disso, contamos com uma lista de duzentas palavras que foram gravadas em estúdio para o projeto ${ }^{5}$ ASLIB do LALLI UnB. Os dados foram transcritos, revisados e testados com os falantes nativos. Todos os dados, com a exceção das gravações feitas em estúdio, foram gravados para a nossa análise acústica, seguindo o seguinte protocolo: (i) seleção escrita do corpus com base em uma avaliação empírica das palavras, (ii) transcrição desses dados em uma nova lista e (iii) leitura em português, das palavras ou frases e, posteriormente, repetidas duas vezes pelo colaborador indígena; a repetição foi necessária para que pudéssemos ter a oportunidade de confirmar os itens e evitar a perda dos dados, no caso de uma das gravações possuírem ruídos.

Todos os dados gerados, tanto nas aldeias, quanto em estúdio, foram gravados de forma digital em formato $W a v$, com taxa de gravação de $48 \mathrm{kHz}$ e 24 bites, e com entrada em mono, usando para isso o microfone head set Audix para evitar distorções por motivo de afastamento ou aproximação da fonte sonora. Os dados somam aproximadamente 20 horas de gravação, formando aproximadamente 400 itens lexicais entre palavras, frases e narrativas. Toda a análise acústica teve como base instrumental o programa Praat ${ }^{6}$. A forma de criar a etiquetas e arquivos do no Praat foi realizada conforme o exemplo da Figura (1), exemplificada em seguida.

Figura 1: Exemplo de arquivos com identificação das etiquetas e segmentação de dados fonéticos gerados e analisados para esta pesquisa.

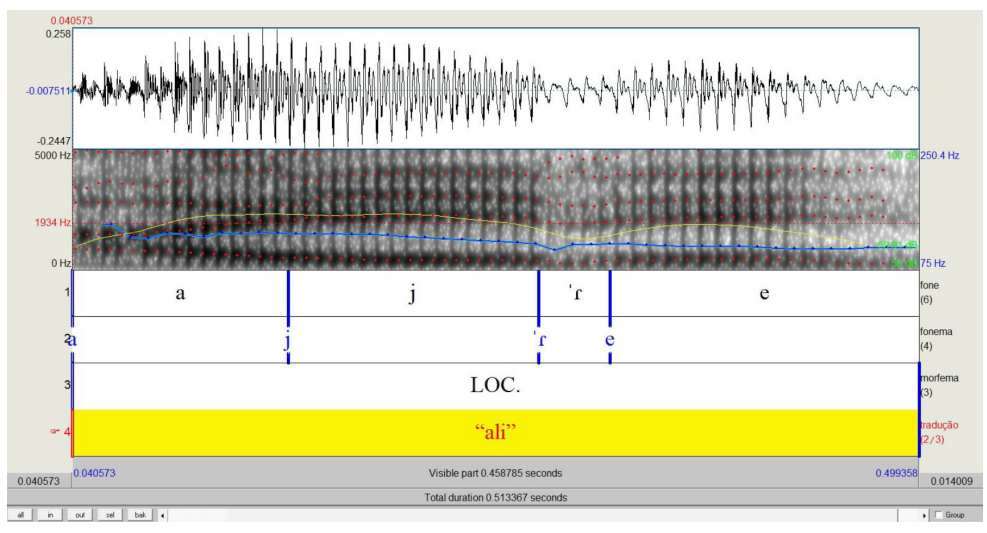

\footnotetext{
${ }^{5}$ Projeto de Atlas Sonoro de Línguas Indígenas Brasileira vinculado ao Laboratório de Línguas e Literaturas Brasileiras da Universidade de Brasília, coordenado pela professora Dra. Ana Suelly Arruda Câmara Cabral.

${ }^{6}$ Disponível na Internet por Sidney Wood, no site:

$<$ http:/ www.ling.lu.se/persons/Sidney/praate.frames.html $>$. Ou em: http://www.fon.hum. uva.nl/praat/. Ou ainda em $<$ http://www.fon.hum.uva.nl/praat/>
} 
Para a análise específica que propomos nesta pesquisa, utilizamos apenas um nível, em que se tem a segmentação fonética dos dados. Preferimos ainda indicar os fenômenos analisados utilizando setas ao invés de etiquetas específicas, conforme pode ser conferido na Figura (2) seguinte.

Figura 2: Exemplo de análise e indicação dos fenômenos fonológicos e realização fonética descritos e analisados nesta pesquisa.

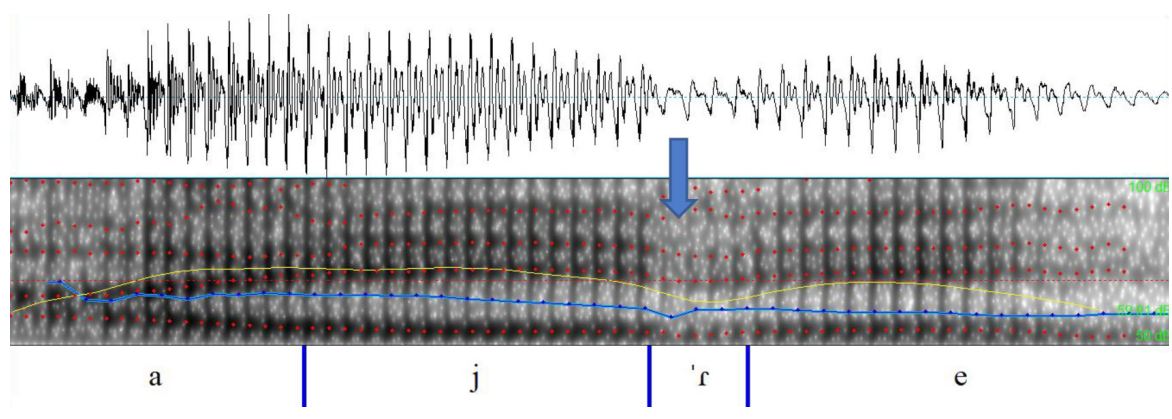

A segmentação do espectrograma de cada som, inclusive a duração das vogais, foram obtidas com base na qualidade mais escura dos formantes e na forma da onda característica de cada som (cf. Ladefoged 1975; Barbosa e Madureira 2015). A duração das vogais com a média normalizada (z-score) foram obtidas a partir de um script rodado no programa gráfico Python(x,y) 2.7.6.1.

\section{Panorama fonológico da língua Tuparí}

Com base em nossa análise preliminar da fonêmica do Tuparí e apoiados na descrição feita por Alves (2004), verificamos que há doze fonemas consonantais, que se dividem nas seguintes formas de articulação: (i) oclusivas /p/, /b/, /k/, / /, $/ \mathrm{t} /$; (ii) nasais $/ \mathrm{m} /, / \mathrm{n} / \mathrm{e} / \mathrm{n} /$; (iii) fricativas $/ \mathrm{s} / \mathrm{e} / \mathrm{h} /$; (iv) vibrante simples (tepe) $/ \mathrm{r} /$; africada $/ \mathrm{t} \mathrm{f} /$ e as aproximantes $/ \mathrm{w} /, / \mathrm{j} /$, que estão distribuídas conforme suas características articulatórias e acústicas descritas na Tabela (1):

Tabela 1: Inventário fonológico das Consoantes do Tuparí

\begin{tabular}{|l|c|c|c|c|c|c|}
\hline & Labiais & Alveolares & Alveopalatal & Palatal & Velares & Glotais \\
\hline Oclusivas & $\begin{array}{c}\mathrm{p} \\
\mathrm{b}\end{array}$ & $\mathrm{t}$ & & & $\mathrm{k}$ & $\mathrm{P}$ \\
\hline Nasais & $\mathrm{m}$ & $\mathrm{n}$ & & & $\mathrm{y}$ & \\
\hline Fricativas & & $\mathrm{s}$ & & & & $\mathrm{h}$ \\
\hline Africadas & & & $\mathrm{t} \int$ & & & \\
\hline Tepe & & $\mathrm{r}$ & & & & \\
\hline Aproximantes & $\mathrm{w}$ & & & $\mathrm{J}$ & & \\
\hline
\end{tabular}

(Adaptado de Alves 2004, p. 34) 
No que se refere aos fonemas vocálicos, a língua Tuparí se destaca por ter uma série de fonemas orais $/ \mathrm{i} /, / \mathrm{e} /, / \mathrm{a} /, / \mathrm{o} / \mathrm{e} / \mathrm{i} /$, outra de fonemas nasais $/ \mathrm{i} /, /$ $\tilde{\mathrm{e}} /$, /ã/, $\tilde{\mathrm{i}} / \mathrm{e}$ / $\tilde{\mathrm{o}} / \mathrm{e}$ e ainda uma outra de fonemas longos orais /i:/, /a:/ /i:/ e /o:/. Todos esses fonemas podem ser observados em suas propriedades articulatórias e acústicas na Tabela (2):

Tabela 2: Inventário fonológico das vogais orais do Tuparí

\begin{tabular}{|c|c|c|c|}
\hline & +Anterior & \multicolumn{2}{c|}{-Anterior } \\
\hline & \multicolumn{2}{|c|}{-Arredondado } & +Arredondado \\
\hline+ Alto & i $\tilde{\mathrm{i}} \mathrm{i}:$ & i $\tilde{\mathrm{i}} \mathrm{i}:$ & o õ o: \\
\hline -Alto & e $\tilde{\mathrm{e}}$ & a $\mathrm{a} \mathrm{a}:$ & \\
\hline
\end{tabular}

(Adaptado de Alves 2004, p. 34)

O inventário fonológico das vogais demostra que a língua Tuparí apresenta, além das vogais orais, vogais nasais e longas.

O padrão silábico da língua Tuparí apresenta estrutura que pode ter uma única vogal $(\mathrm{V})$, uma consoante e uma vogal $(\mathrm{CV})$ ou ainda uma vogal e duas consoantes (CCV, VCC ou $\mathrm{CVC}$ ), mas sendo a realização $\mathrm{CV}$ a de maior ocorrência. Em seguida, descrevemos algumas palavras da língua Tuprí que evidenciam os padrões silábicos nela encontrados.

1) $\mathrm{V} \quad / \mathrm{i}$ 'top/ [i'top] 'olhe'

2) $\mathrm{C}_{1} \mathrm{~V} / \mathrm{ta}$ 'ra/ [ta'ra] 'largo'

3) $\mathrm{C}_{1} \mathrm{VC}_{3}$ /'hat/ ['hat] 'cobra'

4) $\mathrm{C}_{1} \mathrm{C}_{2} \mathrm{~V} \quad /$ 'kwini/ ['kwinĩ $]$ 'forquilha'

5) $\mathrm{VC}_{3} \mathrm{C}_{4} \quad / \mathrm{o}^{\prime}$ ajt/ [o'ajt] 'rabo'

No que diz respeito ao acento em Tuparí, pode-se afirmar que ele é fonológico sendo que ele ocorre principalmente na última sílaba /i'top/ 'olhe' e /he?'em/ 'isto', 'isso', 'esse', mas podendo ocorrer na penúltima /'kwinĩi/ 'forquilha' e ainda na antepenúltima /a' pekiap/ 'amolador'.

\section{Aspectos acústicos e articulatórios da oclusiva glotal}

Argumentamos nesta pesquisa que a laringalização das vogais ocorre principalmente, mas não exclusivamente, em contiguidade com a consoante oclusiva glotal [?].

Para Ladefoged (1971) e Ladefoged e Maddieson (1996), a oclusiva glotal se caracteriza por ter a realização gestual de fechamento total da glote, conforme explicado e destacado na Figura (3). 
Figura 3: Espectrograma de banda larga e forma de onda com janela de $0,5 \mathrm{~ms}$ da palavra Tuparí [,wa?i':] 'pedra'

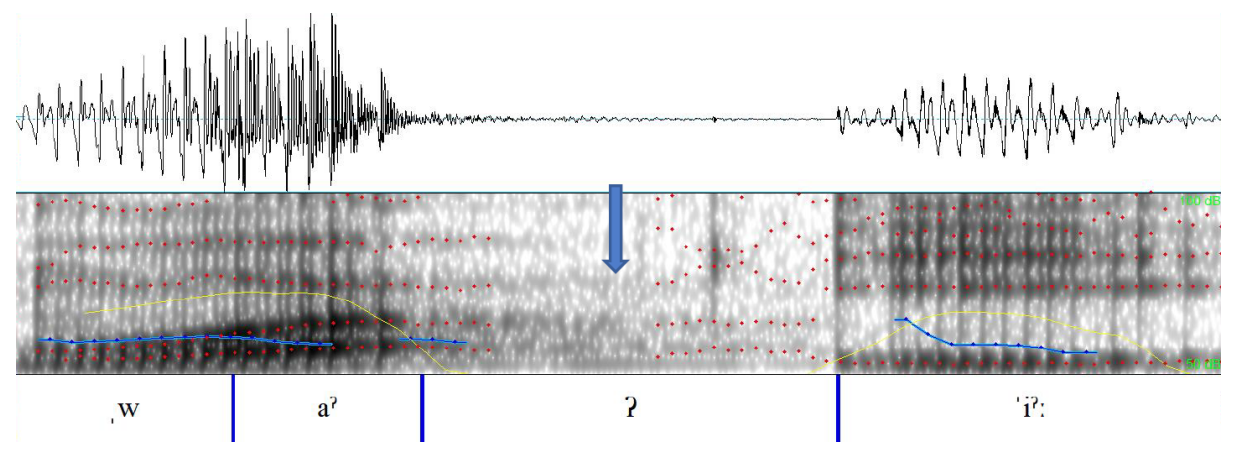

Para Maddieson (2011), as realizações de sons glotálicos (laringais) são conhecidos por serem sons que se realizam com ajustes da laringe, e que são menos comumente usados em relação a outros sons, pois envolvem uma constrição mais estreita das pregas vocais e/ou um movimento da laringe a uma pequena distância para cima ou para baixo na garganta.

A esse respeito, Ladefoged e Maddieson (1996) afirmam que há diferentes realizações da oclusiva glotal nas línguas em torno do mundo e que quando ocorre a oclusiva glotal entre vogais, a realização é tipicamente característica de voz rageada (creak voice); o mesmo ocorre com as vogais laringalizadas, que vão apresentar medidas de (F0) bem menor que as de voz modal (normal). Segundo afirmam os autores, as realizações laringalizadas apresentam como mecanismo principal a realização de músculos que envolvem a região da tiroide, como, por exemplo, o músculo tiroaditenoideo. Junte-se a isso a elevação dos espaços supralaríngeos, motivados pela constrição laríngea. $\mathrm{Na}$ visão de Mattisoff (2000), outros fatores acústicos e articulatórios são importantes para se definir a realização da oclusiva glotal, como por exemplo a queda repentina do pitch e da intensidade (como está indicado pela seta na Figura (3)), retração do corpo da língua, tensão e elevação da laringe.

Especificamente sobre laringalização, Gordon e Ladefoged (2001) e Ladefoged (1971) afirmam que essa realização está associada ao movimento de adução das pregas vocálicas associada à abertura de extremidade suficiente que seja, assim, possível a realização da fonação. Acusticamente, essa realização pode ser percebida ainda como uma série de pulsos glotálicos, realizados de forma irregular e mais espaçada do que a voz modal (voz normal).

\section{Laringalização em Tuparí}

Como já informado anteriormente, para a geração dos dados, gravamos as palavras repetida duas vezes pelos falantes da língua, para que as analisássemos acusticamente no programa Praat. Após esse procedimento, medimos os dois 
primeiros formantes (F1 e F2) para identificar a média normalizada das medidas dos formantes e da duração das vogais. Em seguida, descrevemos, na Tabela (3), as médias normalizadas das frequências dos dois primeiros formantes, que são suficientes para identificar acusticamente as vogais (cf. Ladefoged 1975, Barbosa e Madureira 2015). Além disso, analisamos e descrevemos a duração das vogais orais da língua Tuparí (Tabela 3), utilizando a mesma metodologia, como forma paramétrica de análise e observação.

${ }^{7}$ Tabela 3: Frequências de formantes e duração média das vogais da língua Tuparí em palavras de sílaba CV.

\begin{tabular}{|c|c|c|c|}
\hline Vogal & F 1 (Hz) & F 2 (Hz) & Duração (ms) \\
\hline $\mathrm{i}$ & 305 & 2450 & 0,065 \\
\hline $\mathrm{e}$ & 390 & 2130 & 0,122 \\
\hline $\mathrm{a}$ & 630 & 1350 & 0,143 \\
\hline $\mathrm{i}$ & 420 & 1510 & 0,113 \\
\hline $\mathrm{o}$ & 400 & 1090 & 0,125 \\
\hline
\end{tabular}

Para Gordon e Ladefoged (2001), as características acústicas de laringalização consistem em Frequência fundamental (F0) baixa, ou rebaixada; pulsos glotálicos espaçados; intensidade bem menor se comparada à voz modal (normal); queda repentina de amplitude e F0 menor que a do segundo harmônico.

Com respeito à marginalização, Ladefoged (1971) propõem uma análise que obedece a um esquema baseado em um contínuo de tipos de fonação que, a depender do grau de abertura das cartilagens aritenóides, varia desde a ausência de vibração, realização parecida com sopros, perpassando pela voz normal (modal), até chegar, por exemplo, à oclusiva glotal. Assim, os tipos de constrições da fonação evidenciam várias realizações e combinações possíveis, como voz sussurrada com fôlego (breathy voice), sem fôlego (whispery voice), sem fôlego e rangida (whispery creak), rageada (creaky voice) e voz sussurrada, rangida e sem fôlego (whispery voiced creak). Essas realizações podem ser observadas tanto em línguas africanas como em línguas indígenas brasileiras, como é o caso, por exemplo, do Tuparí e do Latundê. Para Gordon e Ladefoged (2001), esse contínuo de tipos de fonação pode ser entendido como um conjunto de características acústicas e de duração que são comuns às línguas naturais, mas, que em algumas línguas, essas realizações podem ser fonologicamente contrastivas e em outras não.

Gordon e Ladefoged (2001) afirmam ainda que realizações de vogais laringalizadas são comuns na juntura de consoantes que são realizadas com fonação modal, como ocorre, segundo os autores, em alguns dialetos do inglês

\footnotetext{
${ }^{7}$ Os dados para obtenção das médias de F1, F2 e duração foram obtidas a partir de gravação com dois falantes masculinos adultos.
} 
e muitas outras línguas pelo mundo.

No que diz respeito à presença de traços laringais nas vogais, Alves (2004) já apontava que em Tuparí há frequentemente o fenômeno de ${ }^{8}$ laringalização (glotalização) das vogais e que essa ocorrência é parte intrínseca à natureza fonética da língua Tuparí.

Nesse sentido, nosso estudo sobre a língua Tuparí demonstra, à luz das propriedades acústicas, que frequentemente as vogais se realizam laringalizadas, principalmente quando a vogal precede uma consoante oclusiva glotal, como se observa nos exemplos (6-8).

Figura 4: Espectrograma de banda larga e forma de onda com janela de $0,7 \mathrm{~ms}$ da palavra Tuparí [he'?̃ 'ẽm] 'isto', 'isso', 'este'.

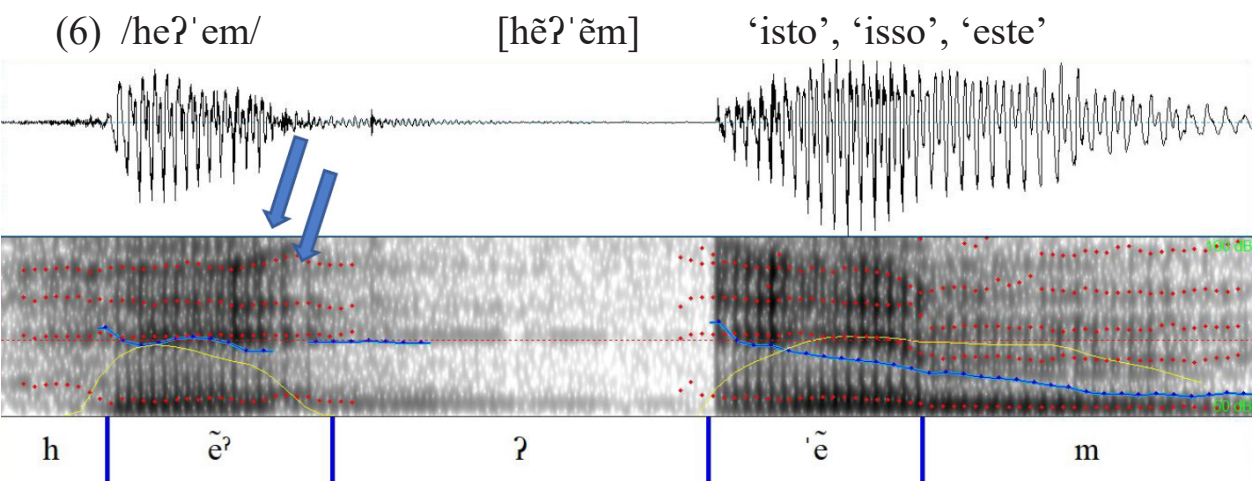

Figura 5: Espectrograma de banda larga e forma de onda com janela de 1,0 ms da palavra Tuparí [kĩ' 'yõ to, ro' $\varepsilon$ ?'] 'pó', 'poeira'.

(7) /ki'yo toro'e?/ [kĩ̄yõ to, ro' $\varepsilon^{2}$ ?] 'pó', 'poeira'

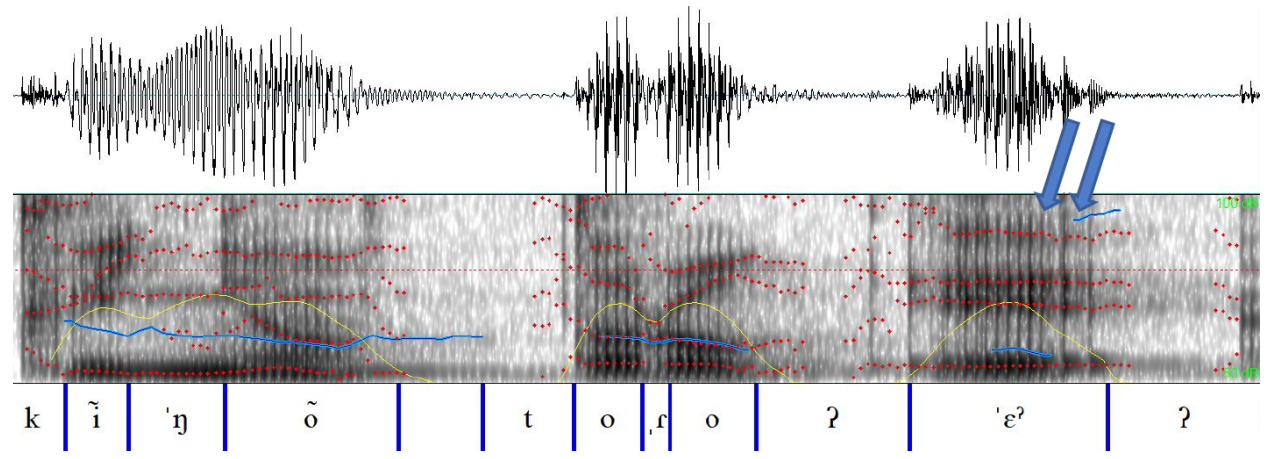

${ }^{8}$ Utilizamos o termo laringalização, ao invés dos termos glotalização (glottal fry) ou creaky voice, que são outros termos comumente utilizados para o fenômeno em questão (Ladefoged 1971). Segundo Kent e Read (2015: p. 19) o termo "glotal tem sido usado como um termo geral para a função laríngea, especialmente a função das pregas vocais". 
Figura 6: Espectrograma de banda larga e forma de onda com janela de $0,5 \mathrm{~ms}$ da palavra Tuparí [,wa?'i':] 'pedra'.

(8) /wa?'i/

[,wa?'i': ] 'pedra'

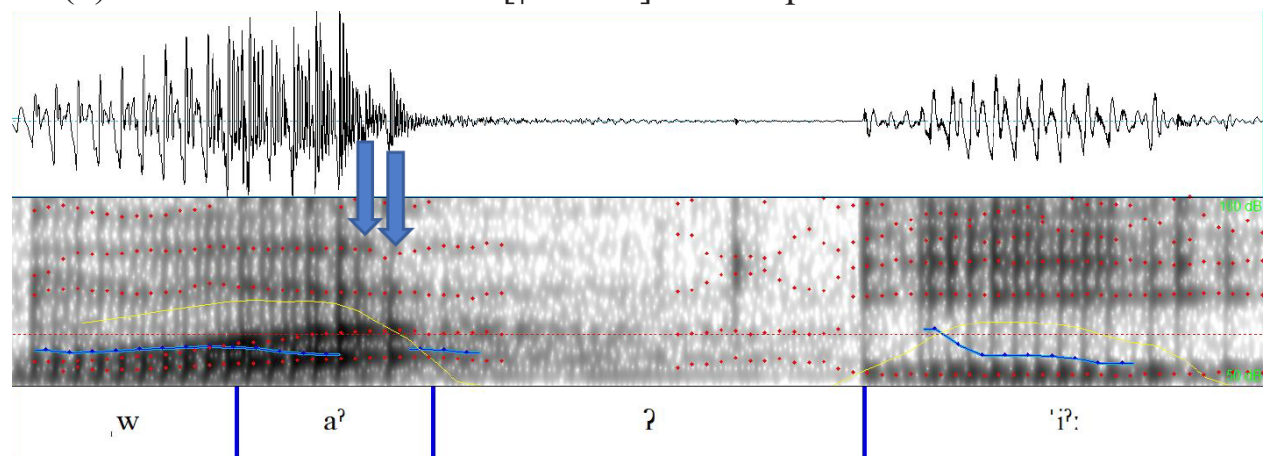

Como se pode perceber, nos exemplos (6-8), as vogais orais ou nasais adjacentes à consoante oclusiva glotal se realizam laringalizadas, porém, como já afirmamos anteriormente, isso não ocorre automaticamente, já que nos dados analisados foi possível evidenciar várias realizações em que a oclusiva glotal não provoca esse processo de laringalização nas vogais adjacentes, como se pode perceber nos exemplos (9-10)

Figura 7: Espectrograma de banda larga e forma de onda com janela de $0,9 \mathrm{~ms}$ da palavra Tuparí [, i? asa] 'cavar (buraco)'.

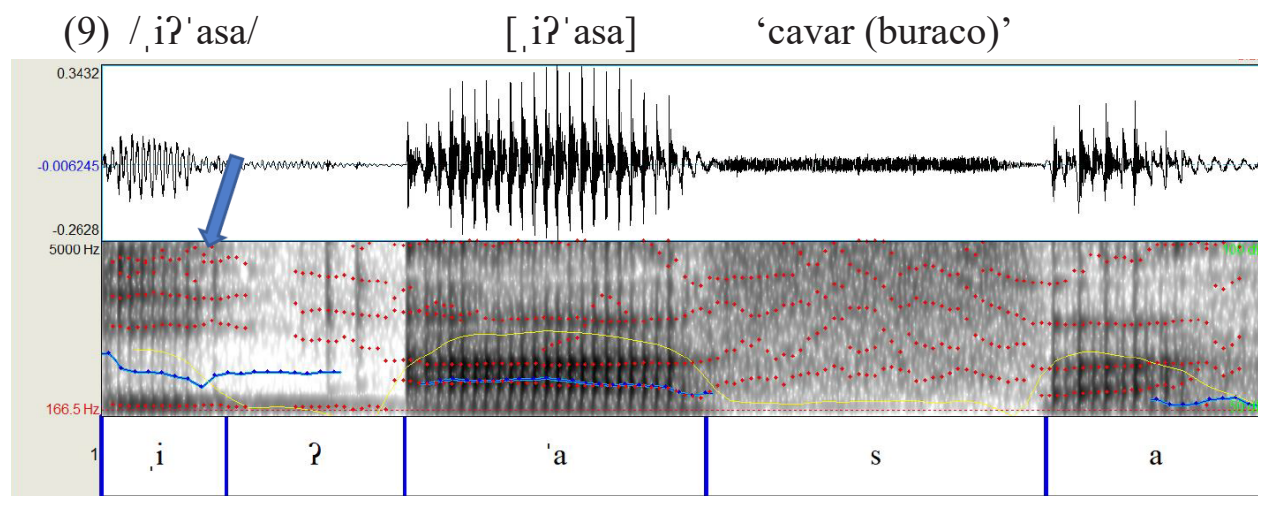


Figura 8: Espectrograma de banda larga e forma de onda com janela de $1,0 \mathrm{~ms}$ da palavra Tuparí [kî' yõ to, ro' $\varepsilon$ ?'] 'pó', 'poeira'.

(10) /ki'no toro'e?/

[kĩ' yõ to, ro' $\left.\varepsilon^{2} ?\right]$ 'pó', 'poeira'

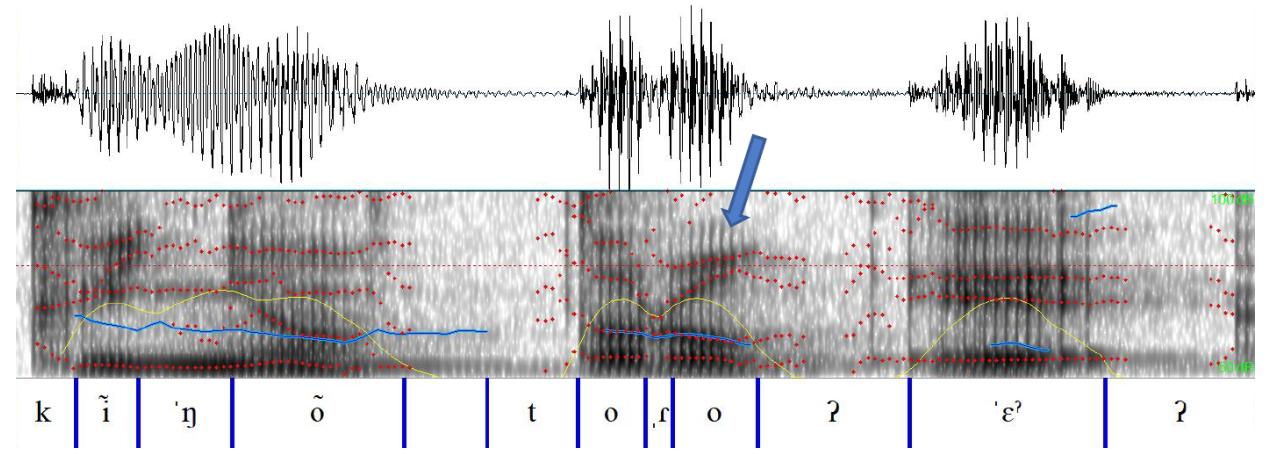

Ladefoged (1971) afirma que a laringalização é um tipo de fonação caracterizada pela vibração lenta das pregas vocais em que as aritenoides permanecem separadas. Característica essa que Alves (2004) descreveu como produção de tipo diferente de vibração das cordas vocais, que resulta em emissão áspera e geralmente em voz mais baixa ou grave.

As imagens dos espetros abaixo são exemplos de realização de uma vogal em sua forma dita normal e/ou voz modal, (imagem à esquerda), onde se nota os formantes se realizando bem mais juntos (conforme indicado pela seta), diferentemente do que ocorre na imagem da direita, que possui os formantes da vogal com realização bem mais espaçada, pois é um exemplos de vogal laringalizada-glotalizada (ou creak voice, conforme Ladefoged 1971).

Figura 9: Exemplos de dois espectrogramas, identificando os formantes com a comparação da realização de vogal com voz normal (modal), imagem à esquerda e vogal laringalizada, imagem à direta.
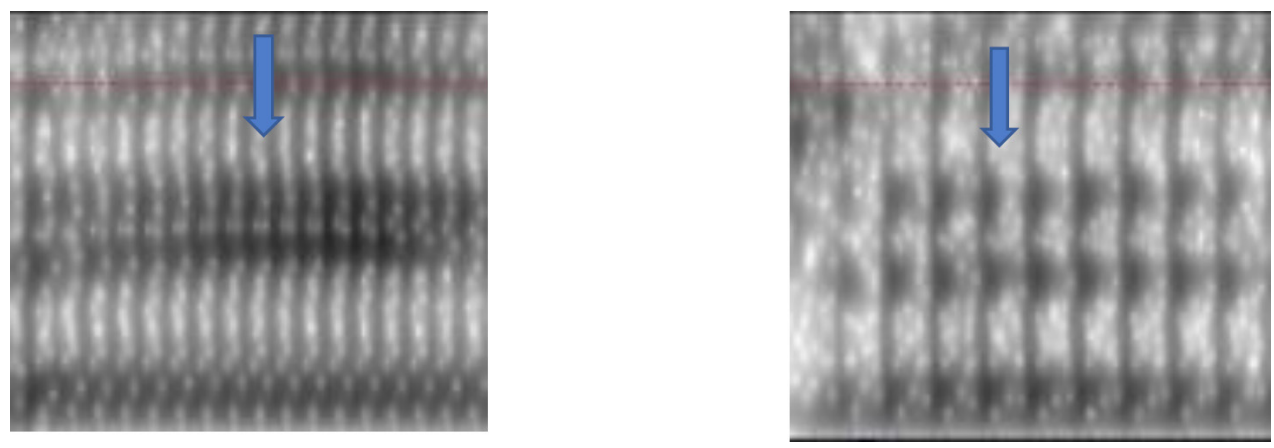

Outro ponto importante que nossa pesquisa pode verificar é que nem sempre a larigalização das vogais ocorre apenas em adjacência à oclusiva glotal, mas também, mesmo que de forma muito rara, em outros ambientes, como em vogais finais, ou seja, seguidas de silêncio, como demostrado nos exemplos (11-15). 
Figura 10: Espectrograma de banda larga e forma de onda com janela de $0,8 \mathrm{~ms}$

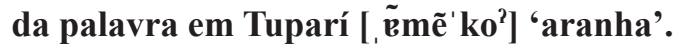

(11) /ame'ko/ $\left[{ }_{1} \tilde{\mathrm{e}} \mathrm{me} \mathrm{e}^{\mathrm{k}} \mathrm{ko}^{\mathrm{T}}\right]$ 'aranha'

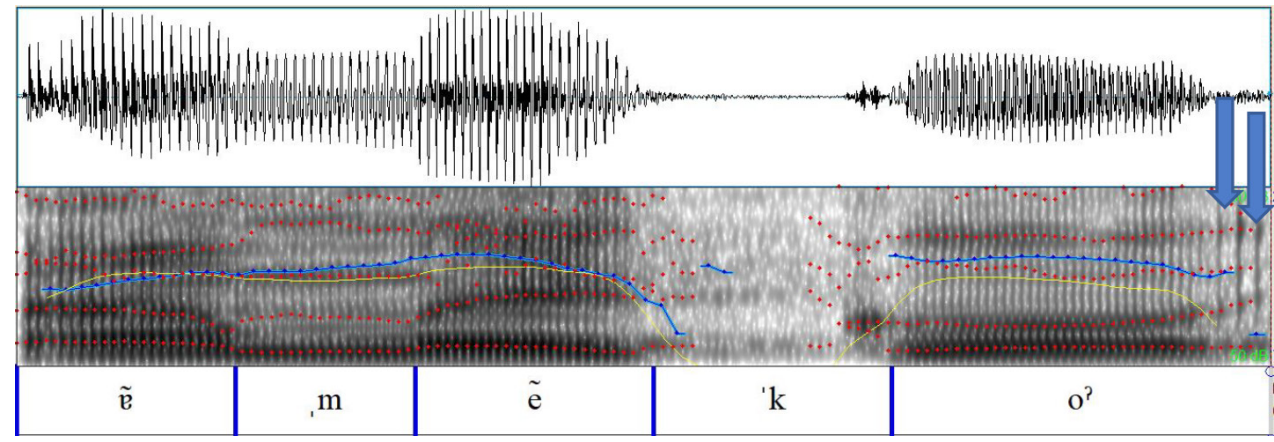

Figura 11: Espectrograma de banda larga e forma de onda com janela de $0,5 \mathrm{~ms}$ da palavra Tuparí [i: 'nke'] 'cheirar'.

(12) /'i:nka/ ['ínke? 'cheirar'

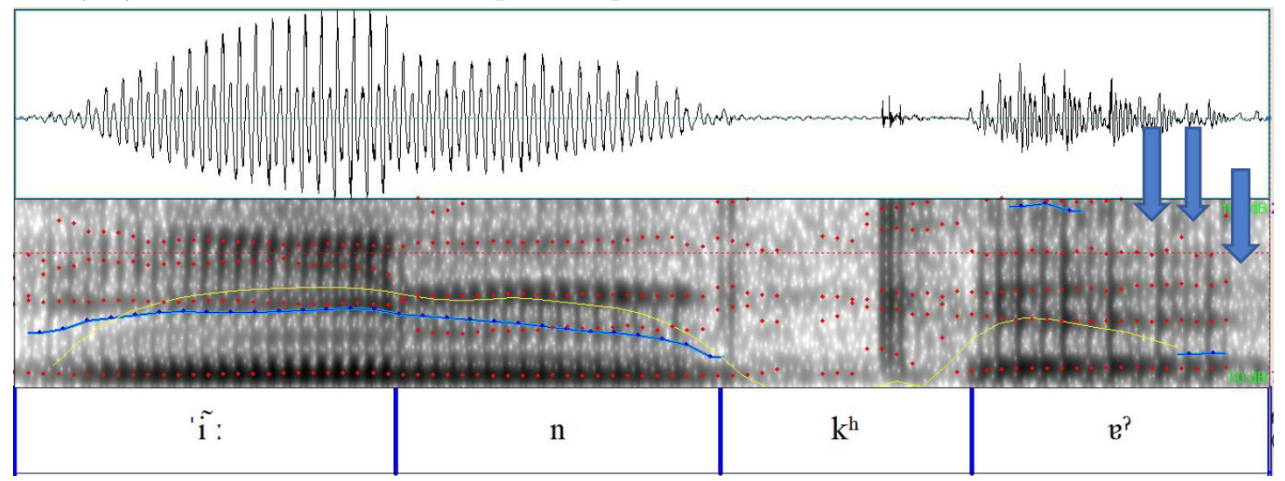

Figura 12: Espectrograma de banda larga e forma de onda com janela de $0,5 \mathrm{~ms}$ da palavra Tuparí $\left[k^{\text {hi }}{ }^{\prime} \varepsilon^{2}\right]$ 'pessoa'.

(13) $/ \mathrm{ki}$ 're/

$\left[\mathrm{k}^{\mathrm{h}}{ }^{\prime}{ }^{\prime} r \varepsilon^{\mathrm{P}}\right]$ 'pessoa'

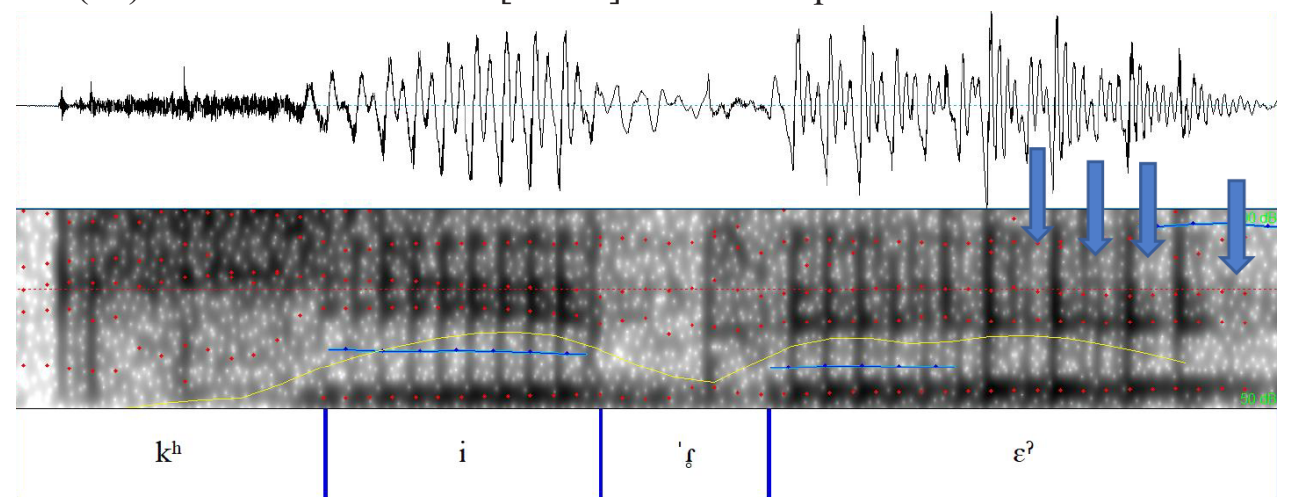


Figura 13: Espectrograma de banda larga de forma de onda com janela de 0,5 ms da palavra Tuparí [, wa'? 'i $\left.\mathbf{i}^{2}:\right]$ 'pedra'.

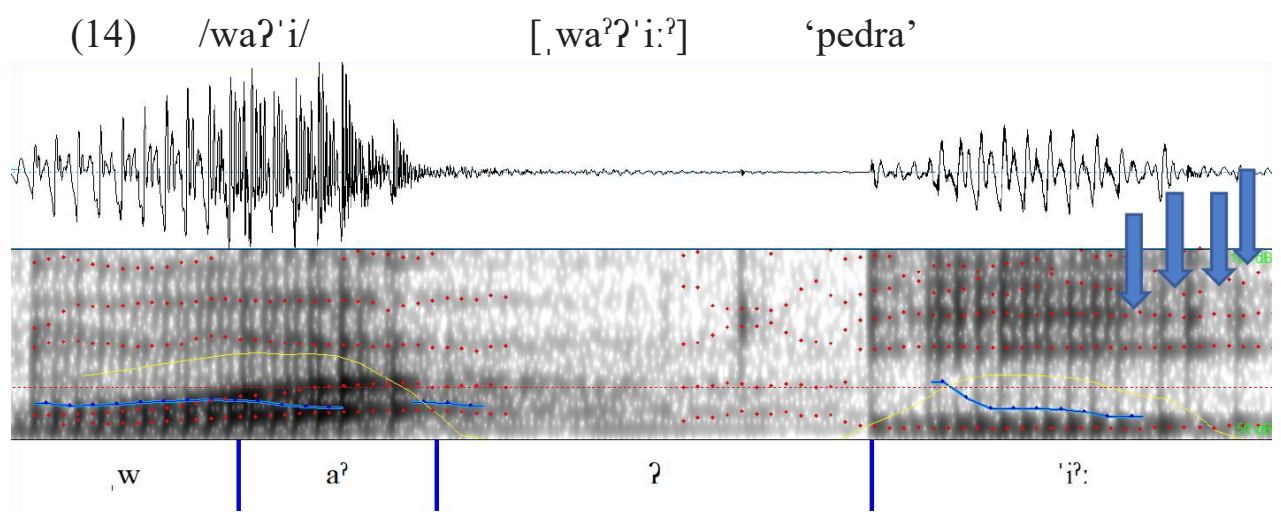

Figura 14: Espectrograma de banda larga e forma de onda com janela de 0,6 ms da palavra Tuparí [ji' $\left.p \varepsilon^{2}\right]$ 'bebida'.

(15) $/ \mathrm{jit} \mathrm{pe} /$

$\left[\mathrm{ji} \mathrm{i}^{\prime} \mathrm{p} \varepsilon^{2}\right]$

'bebida'
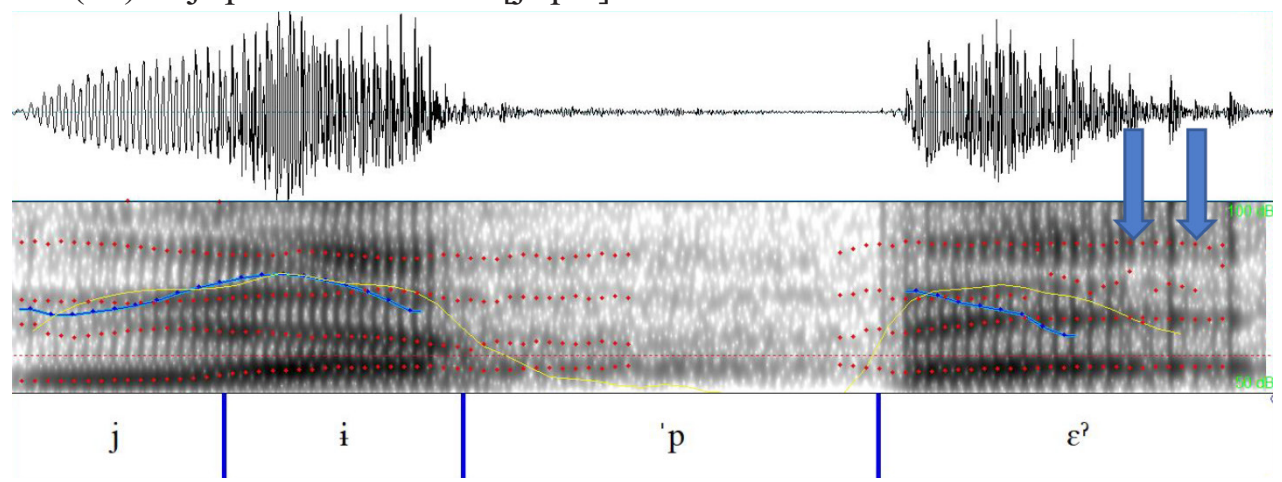

Nota-se nos exemplos supracitados (11-15) que essas vogais, acusticamente, são produzidas não só com uma articulação transiente como também com ocorrência de queda de pitch e de intensidade (cf. Mattisoff 2000). Essa realização resulta, foneticamente, cem uma emissão diferente de vogais não laringalizadas.

Diferentemente do que afirmou Alves (2004), não encontramos pistas acústicas que confirmasse a presença de vogais laringalizadas pela proximidade/ contiguidade a segmentos nasais, como podemos verificar, a título de exemplo, na palavra /'sin/ ['sĩn'] 'fumaça', que serviu anteriormente como exemplo de confirmação da hipótese pela autora e também nas palavras /i'men/ [i'meñ $\left.{ }^{2}\right]$ 'marido' e /imtfi'ro/ [,ĩmtfi'ro] 'mandi sapo', exemplos (16-18) 
Figura 15: Espectrograma de banda larga e forma de onda com janela de $0,5 \mathrm{~ms}$ da palavra Tuparí ['sĩ:y] 'fumaça'.

(16) /'sin/

$$
\text { ['si:y] }
$$

'fumaça'
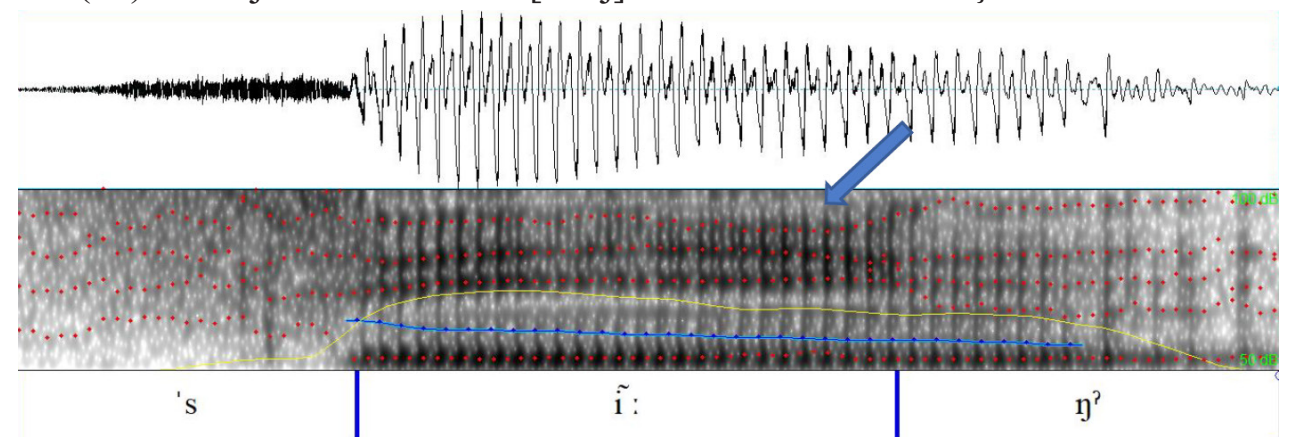

Figura 16: Espectrograma de banda larga e forma de onda com janela de $0,5 \mathrm{~ms}$ da palavra Tuparí [ĩ' mẽn'] 'marido'.
(17) /i'men/
[1' mẽn $\left.{ }^{2}\right]$
'marido
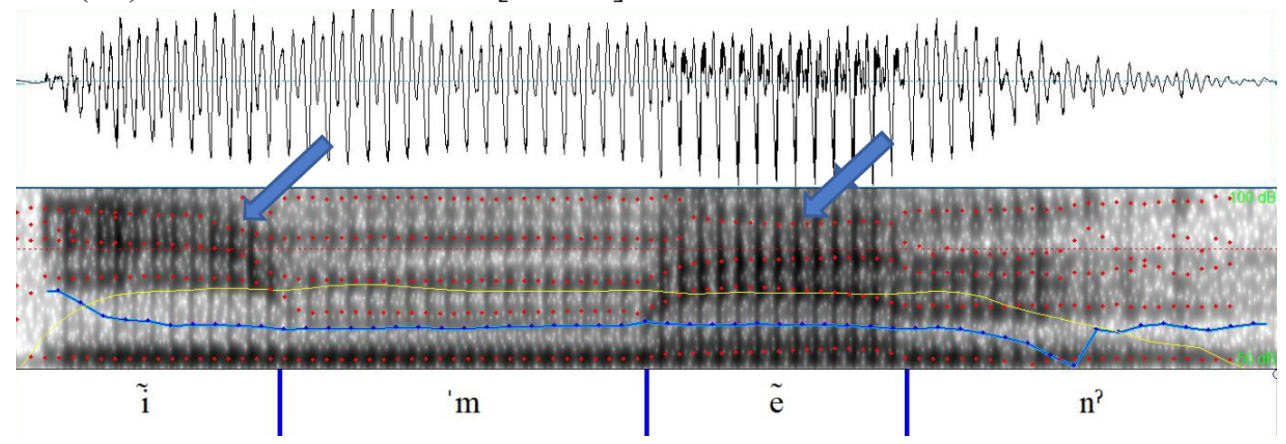

Figura 17: Espectrograma de banda larga e forma de onda com janela de 0,7 ms da palavra Tuparí [, îmtfi' ro] 'mandi sapo'.
(18) /imt fi'ro/
[. $1 \mathrm{mt} \int \mathrm{i}^{\prime}$ ro $]$
'mandi sapo'
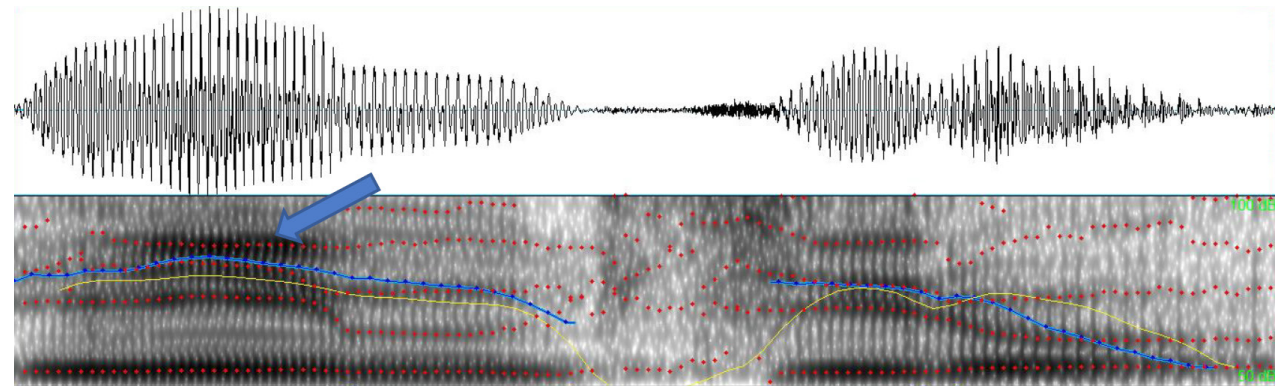
$\tilde{i}$
$\mathrm{m}$
\begin{tabular}{l|l|l|} 
tf & i & s
\end{tabular}
o 
Vale ressaltar que, apesar da grande frequência de realizações de vogais laringalizadas que ocorrem em Tuparí, elas são de caráter fonético e não fonológico, diferentemente do que acontece em outras línguas indígenas como, por exemplo, Latundê, pertencente ao subgrupo Nambikwára do Norte (cf. Telles 2013).

\section{Considerações finais}

O presente trabalho objetivou a análise e a descrição da presença de traço laringal-glotal nos segmentos vocálicos da língua Tuparí. Estudos anteriores sobre a língua (Alves 1991 2004) já apontavam para essa ocorrência, porém sem lançar mão do aparato técnico e metodológico da fonética acústica, o qual assumimos o protagonismo neste tralho. Conforme afirma Ladefoged (1971), a investigação com base na fonética experimental permite ao pesquisador identificar as realizações fonéticas que nem sempre são fáceis de perceber somente de oitiva.

Nesse sentido, a investigação por meio da fonética experimental nos proporcionou a confirmação de que o traço laringal está presente, em grande parte dos dados, tanto em segmentos vocálicos adjacentes à oclusiva glotal como em vogais em posição final de palavra. Outro ponto importante é que não encontramos evidências acústicas, nos dados disponíveis, que pudessem confirmar a realização de vogal laringalizada em consequência da proximidade com consoantes nasais, como afirmou Alves (2004). Mas, por outro lado, essa investigação nos permitiu identificar consoantes laringalizadas, mesmo que em apenas três exemplos.

É importante lembrar ainda que a presença de traços laringais nas vogais não acarretam distinções fonológicas, mas sim aspectos de variações fonéticas.

Esperamos que os resultados de nosso estudo possam contribuir tanto para os estudos linguísticos sobre o Tuparí e sobre a família a que pertence, como também para inventários das línguas indígenas brasileiras.

\section{Referências}

Alves, Poliana Maria. Análise Fonológica Preliminar da Língua Tuparí. Dissertação (Mestrado em Linguística). Brasília: UnB, 1991.

. O léxico do Tuparí: proposta de um dicionário bilíngue. Tese (Doutorado em Linguística). Araraquara, SP: Universidade Estadual Paulista, 2004.

Barbosa, Plínio Almeida; Madureira, Sandra. Manual de fonética acústica experimental: aplicações a dados do português. São Paulo: Cortez, 2015.

Cabral, Ana S.A.C; Aragon, Carolina C. Relatório de identificação linguística da língua Akuntsú. Departamento de índios Isolados, Fundação Nacional do Índio. Brasília. Ms, 2004a.

CABRAL, Ana S.A.C; Aragon, Carolina C. A posição da língua Akuntsú na família linguística Tuparí. In: Anais do IV Congresso Internacional da ABRALIN, 2005, p. 
1533-1539. Disponível em: <http://www.abralin.org.br>. Acesso em 26 de abril de 2018.

CASPAR, Franz; Rodrigues, Aryon D. Versuch einer Grammatik der Tuparí-Sprache. Ms. 1957.

Caspar, Franz; Rodrigues, Aryon D. Esboço da Gramática da Língua Tuparí. Enrique Huelva Unterbäumen et. al. (Tradução). Brasília, DF: LALLI, 2017.

Gordon, M.; Ladefoged, P. Phonation types: a cross-linguistic overview.

Journal of Phonetics. v. 29, p. 383-406, 2001.

Ladefoged, Peter. Vowels and Consonants: an Introduction to the Sounds of Languages. Malden/MA, USA: Blackwell Publishing, 2001 1971. Preliminaries to Linguistic Phonetics. Chicago: University of Chicago Press, . A Course in Phonetics. California, Los Angeles: Harcourt Jovanovich, Inc. 1975. ; Maddieson, Ian. The Sounds of the World's Languages. Massachusetts-USA: Cambridge, 1996.

Kent, Ray D. e READ, Charles. Análise Acústica da Fala. Alexsandro Meireles (trad.). São Paulo: Cortez, 2015.

Lucy, Seki. Aspectos Morfossintáticos do Nome em Tuparí. In: Aryon Rodrigues e Ana Suelly A. C. Cabral (Org.). Atas da ANPOLL. Belém: Editora Universitária UFPA, tomo I, 2002, pp.298-308.

Maddieson, Ian. Glottalized consonants. In: DRYER, Matthew S.; HASPELMATH, Martin (Orgs.). The World Atlas of Language Structures Online. Munique: Max Planck Digital Library, 2011. Disponível em: <http://wals.info/chapter/7>. Acesso em: 14 mar. 2018.

MakurÁP, Maiza. A alimentação tradicional do povo Makuráp/ RO e suas mudanças. 2015, 75fls. Monografia, Licenciatura em Educação Básica Intercultural, Universidade Federal de Rondônia, 2015.

Rodrigues, Dall'Igna Rodrigues. Silêncio, Nasalidade e Laringalidade em Línguas Indígenas Brasileiras. Letras de Hoje, v. 38, n. 4. Porto Alegre, 2003. p. 11-24.

. Línguas Brasileiras: para o conhecimento das línguas indígenas. 4. ed. São Paulo: Loyola, 2002.

. Tupí Languages in Rondônia and in Eastern Bolívia. In: Leo Wetzels (ed), Language endangerment and endagered languages: linguistic and anthrpological studies with special emphasis o the languages and cultures of the Andean-Amazoniam border area. Leiden: Universiteit Leiden, 2007.

Telles, Stella. Traços laringais em Latundê (Nambikwára do Norte). Belém: Mus. Emílio Goeldi, 2013.

Tuparí, Raul Pat Awre. "OTE MA'Ẽ - Reflexões Sobre a Escrita da Língua Tuparí". 2015, 84 fl. Monografia de conclusão de curso, Educação Básica Intercultural, Universidade Federal de Rondônia- campus de Ji-Paraná, 2015. 